\title{
Influence Of Hotel Enterprises' Social Cultural Practices On Community Empowerment Along The Coastal Tourism Circuit In Kenya
}

\author{
Samwel Oriyama Ikwaye \\ Kenya Methodist University \\ Thomas Anyanje Senaji \\ Kenya Methodist University \\ Risper Awiti Orero \\ Kenya Methodist University \\ Methuselah Bichage Gesage \\ Karatina University
}

\begin{abstract}
The study sought to assess the influence of socio-cultural practices on community empowerment along the coastal tourism circuit in Kenya. Data was obtained from 210 respondents who included hotel managers, employees from the local community, suppliers of goods and services to the enterprises including beach operators as well as civic leaders from Mombasa, Kwale and Kilifi counties. Hotel managers, employees, suppliers and beach operators completed a self administered questionnaire while civic leaders were interviewed. Results showed that socio-cultural practices adopted by the hotel enterprises influenced community empowerment, the influence of promotion of local heritage being significant. At the same time, it was illustrated that social innovation partially mediates the influence of the practices on community empowerment. Based on the findings, the study recommends enhanced adoption of elements of preservation of local culture and adherence to legal frame work to improve on the influence of socio-cultural practices on community empowerment. Lastly, it recommends enhanced adoption of elements of social innovation so as to improve its mediating effect.
\end{abstract}

Key Words: Community Empowerment, Social Innovation, Socio-cultural Practices

\section{INTRODUCTION}

Tourism and hospitality investments apart from seeking to empower locals socio-economically seek to recognize and embed the socio-cultural practices and norms of the local communities. In doing this, they seek to encourage sustainable business environment in which entrepreneurs and host communities mutually coexist. In tourism industry, socio-cultural sustainability is concerned with the social interaction, relations, behavioral patterns and values between people (Roberts \& Tribe, 2008; Mason, 2012). It seeks to ascertain that since the main import of the industry entail harnessing economic value of the interaction between tourists and host communities; the interaction does not disadvantage the local communities' culture, practices as well as norms. A respectful interaction between hosts and guests, involvement of the local people and recognition of the contribution of traditions and culture to the tourist experience are key issues for sustainable businesses (Roberts \& Tribe, 2008). 
According to Nadda, Dadwal, Mulindwa, and Vieira (2015), tourism is now seen as a viable tool for economic development and social change in most developing countries. This view was confirmed by Moufakkir (2012) who argued that tourism is an agent of change, a global phenomenon which plays a significant role in the socio-cultural evolution. It is sometimes seen as asymmetrical in terms of power relations where the affluent countries of the west are the generators of tourism and the less affluent countries are at the receiving end (Britton, 1982). Nonetheless, many people including those in rural areas see tourism as an economic and sociocultural process for all those who participate in its activities. A key aspect to be considered here is how the processes of tourism's global expansions have played themselves within the developing world at the national, regional and local levels (Scott Williams, Baker, Brace-Govan, Downey, Hakstian, \& Webb, 2011).

\section{SOCIO-CULTURAL PRACTICES AND COMMUNITY EMPOWERMENT}

In developing countries, tourism and accommodation industry might have impacts on the socio-cultural conduct of people. Generally, governments in such countries have employed a top down type of tourism planning model where all decisions of developing and promoting tourism are carried out by the central government leaving the local community destinations with little or no input is the activities that affect their livelihoods. This has led to some commentators (Richards \& Hall, 2003) arguing that the forces of modernisation have turned the local communities into products sold to tourists and consumed as commodities. Local communities in such countries are expected to conform to the tourists' expectations of backward neighbourhood, which has not been tainted by modernisation and expected to impinge on its rustic rural tranquillity. The question of authenticity in tourist experiences arises when cultural traditions get modified and altered for tourist consumption. At the same time, commoditization can lead to pseudo-events that are planned to be convenient for tourists which might lead to a falsification of the traditional meaning of the event (Mason, 2012). Consequently cultural promotion through tourist education and initiatives to promote and enhance appreciation for cultural and historic heritage are indicators and actions outlined by Roberts and Tribe (2008).

Also significantly important and related to socio-cultural impacts of socio-entrepreneurial practices on tourism is the aspect of environmental conservation. Most touristic consumables are related to nature and the environment. National parks, wildlife, natural or indigenous forests or even sandy coastlines are all associated with the environment. Respectful consumption of these resources would strengthen not only the socio-cultural diversity of different destinations but also ensure sustainability of touristic activities and destinations. Consequently, environmental conservation is an important aspect of sustainable tourism activities. Studies indicate efforts of communities adjacent to touristic facilities with conservation attempts as a move to ensure sustainability of gains associated with socioenterprises in tourism. For instance Birch, Thapa, Balmford, Bradbury, Brown, Butchart, and Peh (2014) reports on the commendable efforts of Forest of Hope Association (FHA), a small Rwandan NGO concerned with the conservation of the Gishwati Forest Reserve in Western Rwanda. Established in January 2012, FHA emerged from - and builds on - the Gishwati Area Conservation Programme (GACP), which began in 2008. FHA's main activities are conservation education, improving local livelihoods and facilitating research on the biodiversity of the Gishwati Forest Reserve. During four years of operations, impressive conservation impacts have been achieved: illegal use of the forest has declined sharply; the size of the reserve increased from 886 hectares to 1,484 hectares; and the chimpanzee population grew from 13 to 20 . Social impacts felt include the organisation generating 29 jobs, of which 25 were filled by local people; 13 school eco-clubs were established; and the capacity of 10 local cooperatives 
were increased. Similar outcomes are attributed to Kibale Association for Rural and Environmental Development, Uganda among others.

Related to the authenticity in cultural events is the authenticity in food and drink provided. The modern catering side of the accommodation industry has been criticized for offering 'international' menus with many imported ingredients or imitations of traditional local dishes. Sustainable business practices would be encouraging tourists to visit local food producers, providing local products and supporting organic and environmentally friendly agriculture and food processing industries (Swarbrooke, 1999).

Also significant in relation to socio-cultural practices of socio-entrepreneurs in tourism is the management of their interaction with local communities in respect to children. Investors in the tourism sectors have been variously accused of participating in or abetting un-culturally sound practices especially among natives (Omondi 2003; Jones, 2006). Two issues stand out in this regard: child labour and child sex tourism which not only negatively impacts the culture of the host communities but also the lives of children and youth. The International Labour Organization (ILO) defines child labour as work that deprives children of their childhood, their potential and their dignity, and that is harmful to their physical and mental development. A key aspect of child labour is that it is likely to interfere with children's right to education. Recent figures from the ILO show that 1 in 6 children work. 218 million children aged 5-17 are involved in child labour worldwide mainly in the Asia/Pacific region and Sub Saharan Africa (CRIN, 2010). However, child labour also occurs in industrialised countries. The ILO (1999) warns that in Central and Eastern Europe child labour has reappeared since countries there have made the transition to a market economy. Studies have also demonstrated prevalence of child labour in the tourism industry (Pluss \& Tourismus, 1999). According to the researcher, children are omnipresent in the tourism industry but not always in places where they can be easily noticed. Highly visible are those children who are actively scrambling for a share in the trade (for example: children selling fruit on the beach or craft at markets).

However, the children behind the scenes are virtually invisible (for example: children cleaning rooms in hotels). In the 2002 ILO report 'A Future without Child Labour' it was noted that many children work in the informal economy which surrounds and supports the formal tourist industry. Usually when we think of child labour, we think of children slaving away in sweatshops, factories or mines or of children working on the streets in the informal sector. These are the 'visible' forms of work children do but the focus of the media and politics on these types of work has obscured the fact that there are also 'invisible' forms of work that children do hidden away from the public eye, at home, on farms or behind closed doors that also support the tourism industry (Bliss, 2006, p.3). Many of these children are young girls (IPEC, 2009). Maggie Black thinks the total number of children working in tourism is much higher than the rough estimate of 13 to 19 million children because the children doing 'invisible' work in the informal sector are excluded. She also gives various examples of how children can be doing work in the informal sector which in turn supports the formal sector in tourism like in plantations or in brick making (Bliss, 2006, p.7).

Commercial sexual exploitation is another form of child labour that has evolved in most touristic destination worldwide. It evolved as an appendage of sex tourism. Otherwise known as tourism prostitution, sex tourism may be defined as tourism for which the main motivation or at least part of the aim of the trip is to consummate or engage in commercial sexual relations (Ryan \& Hall 2001). Studies indicate that in recent years, the number of men (and women) travelling to foreign destinations usually in the Third World seeking sex tourism has increased tremendously (Herold et al., 2001; Ryan \& Hall 2001). In the past, notorious destinations for 
sex tourism had been mainly the Southeast Asian countries such as Bangkok ('the red light capital of the world'), Thailand (sometimes called 'Thighland'), the Philippines, Indonesia, South Korea and Sri Lanka (Enloe 2002; Ryan \& Hall 2001). Today, sex tourism has spread to other regions of the world including Goa (a coastal state of India), Cuba, the Dominican Republic, Brazil, Costa Rica, Eastern Europe and a number of African countries such as Kenya, Tunisia, South Africa and The Gambia (Ryan \& Hall 2001, Enloe 2002; Chissim 1996).

According to the Global study (2016), in Sub-Saharan Africa, increase in tourism and hospitality activities as per the data obtained from UNWTO in the last 20 years has correspondingly seen rise in Child Sex Tourism (CST) and Commercial Sexual Exploitation of Children (CSEC), although empirical data to support this is lacking. According to the study, the increase in diverse modes of travel and tourism has been found to attract visitors to once remote locations, and foreign direct investment which is bringing in unaccompanied male and female workers. The region is reported to be seeing a surge in mobile data use with mobile internet traffic expected to rise 20-fold by the end of the decade. Meanwhile, traditional norms continue to pose risks for children, particularly their low social status and child marriage. At the same time, while most countries have ratified relevant international conventions, commitments have not translated into meaningful action for children and only a small percentage of child victims receive the help they need. Specifically, evidence gathered through the research indicated that CST and CSEC are on the rise in Africa. According to the study, while tourism had historically been associated with North and West African countries (such as Morocco and Senegal), an influx of tourists seeking sex with children - including African travellers - was now being reported elsewhere in the region. Studies conducted in Kenya, Madagascar, Senegal, South Africa and The Gambia in 2013 found that CST and CSEC were identified as a problem by stakeholders, community members and child victims in all the five countries (ECPAT Netherlands, 2014). Members of the ECPAT International regional network pointed to Benin, Cameroon, Côte d'Ivoire, Ghana, Kenya, Madagascar, Mauritius, Morocco, Nigeria, Senegal, South Africa, The Gambia and Tanzania (Zanzibar) as major destinations for travelling child sex offenders.

Similarly, IRIN (2009) noted that as the tourism industry undergoes dramatic changes, with the emergence of new online, unregulated modes of accommodation and transportation, children's vulnerability is also rising. In particular, research revealed a trend toward the use of new types of infrastructure for SECTT, beyond traditional beach-front attractions. Nontraditional venues include settings associated with "volun-tourism" and other child-contact institutions; travel infrastructure linked to national and foreign direct investment; military bases and camps, refugee and migrant detention centres, policing infrastructures and peacekeeping missions; the adult sex trade and entertainment industry; and online platforms, among others. Almost all countries in Sub-Saharan Africa have ratified the major international conventions protecting children against SECTT-related crimes. However implementation has been weak, so these commitments have generally not translated into meaningful action or change for children. Research for this report indicates that the same is true with regard to national legislation: even when updated laws are in place, enforcement is insufficient, leaving children vulnerable to SECTT and other forms of exploitation. Moreover, corruption often compounds these difficulties, creating an environment where perpetrators act with impunity. The Code of Conduct for the Protection of Children from Sexual Exploitation in Travel and Tourism has been adopted by 24 private businesses, mainly hotel groups and travel agencies, in the region. Unfortunately, greater scrutiny at leading hotels has driven SECTT offenders to use guesthouses, private rentals and low-budget hotels. 
In Kenya, the commercial sexual exploitation of children in coastal areas is reported to be a shocking violation of their rights, and a reflection of the profound risk potentially faced by all children in within the country (Jones, 2006). Some ten to fifteen thousand girls living in coastal areas are said to be involved in casual sex work - up to $30 \%$ of all 12 to 18 year olds living in these areas. A further two to three thousand girls and boys are involved in full-time year round commercial activity. Many full-time child sex workers have migrated to the coast from other parts of the country, and have often been inaugurated into sex work before they arrive. The sexual exploitation of children is not limited to coastal areas or to tourists, but can be found in communities across Kenya. About one in ten children involved in sex work are initiated before they reach puberty. The level and acceptance of sexual exploitation of children in coastal areas puts all children in Kenya at risk. It reflects a fundamental breakdown and corruption of families and communities, and a failure of the authorities to provide protection to children and to prosecute those responsible for promoting and profiting from child sex work. Tourists that exploit children are at the centre of a ring of corruption that involves many from the local community. Child sex workers are often compelled to deliver sexual services sometimes even from locals including beach boys, bar staff, waiters, and others in order to access tourists. During the low tourist season, the local market for child sex workers keeps the system going. The sexual exploitation of children therefore thrives because of the complicity of a broad section of the local community. While some children are driven into transactional sex because of poverty, the high level of acceptance of child sex work in coastal communities makes it relatively easy for children to drift into casual sex in exchange for no more than extra pocket money. Many younger girls reported that they begin in local bars to gain experience and money to allow them to buy clothes, accessories and hairstyles that will enable access to the tourist market.

The consequence of inaction against child sex tourism and child trafficking for sexual purposes is the damage to the destination's reputation (ECPAT International, 2007). Child sex tourism and child trafficking for sexual purposes in tourism creates a negative dependency that becomes unsustainable. Destinations that plan to genuinely develop as a "continental tourism destination", must focus on developing themselves into sustainable and positively attractive entities. With reports indicating that tourists more than ever, are aware of social issues and are utilising their "customer power", efforts aimed at correcting such social vices such as CST and child trafficking needs to be sorted out. The industry in realising this fact and as a moral responsibility have created programmes within themselves and joined the Code of Conduct for the Protection of Children from Sexual Exploitation in Travel and Tourism, as an industry initiative to combat this vice. This study sought to assess how socio-cultural practices of hospitality and tourism enterprises impacts empowerment of communities.

\section{SOCIAL INNOVATIONS}

Evidence indicates that social innovation has the potential to provide solutions in various sectors, tourism included as an important developmental factor (Petrou \& Daskalopoulou, 2013). This according to the researchers is attributed to its ability influence the transformation of community social capital from being customer oriented to community oriented. Van Oort and Lambooy (2014) in supporting this assertion emphasised that social innovation ensures environments that enable the development of prosperous businesses and start-up companies in which all stakeholders focus on better care for the working environment and the rules of the game, and less on the process. It therefore offers an important competitive edge for regions and countries. According to lkier, Milojica, and Roblek (2017), technological development is added to the social innovation as connotation of new service solutions. The researchers observed that based on an analysis of theory and practice, social innovations incorporates both technological and/or organizational innovations. Its importance is different 
an varies depending on the level of socioeconomic development of destinations. In more rural destinations they are more orientated in social solutions and missions. Social innovation as a source of social solutions in tourism therefore is concerned with transferring innovation knowledge and providing products, services and solutions to the needs of the tourists and community stakeholders.

Hospitality and tourism is a complex sector that has an important role in social and economic development of the society (lkier et al., 2017). The progress of the sector in any destination includes a multi stakeholder for which it presents a source of economic and social progress and a cause of negative effects at a social, environmental and economic level (Carlisle, Kunc, Jones, \& Tiffin, 2013). This is the reason why close attention should be taken with regard to the industry in order to ensure sustainable growth, which is represented by the establishment of the innovative environment, which ensures hospitality and tourism entrepreneurial projects that do not present value added only for the tourist, but also for all the local stakeholders (Laeis, Laeis, G. Lemke, \& Lemke., 2016; Pranicevic \& Peterlin, 2015). Social innovation solutions in the industry thus represent an important developmental factor, due to their influence on the transformation of the sector (Petrou \& Daskalopoulou, 2013). Pace (2016) observed that it is important for tourism to focus on social innovations since it allows for an analysis of the cultural relationship involved in the adoption of innovation. In the process of the adaptation of the innovation, consumers have the option to use new products in different ways that transform social practices associated with the product. In order to achieve this, consumers should be recognized as cultural agents who re-enact culture in the consumption process which can influence on the transforming practices associated with new products (Mosedale \& Voll, 2017).

Existing literature illustrates that sustainable model of sharing economy has an important influence on launching social innovation in tourism combined with the internet technologies (Roblek, Stok, \& Mesko., 2016). It entails going for a social platform and mobile applications that allow things as sharing knowledge, products and services among consumers, business to customer and business to business. The online platforms have re-worked hospitality relationships and tourists get the opportunity to enact their agency and become cultural agents (Sigala \& Kyriakidou , 2015). In this regard, social innovations became a part of the technological and/or organizational innovations after the year 2008 with the launch of a third industrial revolution. Technological breakthrough which enables the progress of (social) practices in tourism has changed the supply chain of tourist products. The technological development played an important influence on the changing business environment within tourism and hospitality industry. The educational providers became aware of the need to have the ability of developing and acquiring the basic concepts of learning about using information and communication technology and computer literacy, which would play an important role in the personal development and economic and social development of the society (Bisson, Stephenson \& Viguerie, 2010).

Social innovation is a new combination and/or new configuration of social practices in certain areas of action or social contexts prompted by certain actors or constellations of actors in an intentional targeted manner with the goal of better satisfying or answering needs and problems than is possible on the basis of established practices (Howaldt \& Kopp, 2012). This definition suggests that for an activity to qualify as a social innovation, it must meet four criteria: it must be new, it must address a social challenge, the intent must be to create equality, justice and empowerment and the effect or end result must be equality, justice and empowerment. The key distinction is that social innovation deals with improving the welfare 
of individuals and communities through employment, consumption and/or participation, its expressed purpose being to provide solutions for individual and community problems"

Mulgan et al. (2007) observed that outcomes of social innovation are all around us and include self-help health groups and self-build housing; telephone help lines and telethon fundraising; neighbourhood nurseries and neighbourhood wardens; Wikipedia and the open university; complementary medicine, holistic health and hospices; microcredit and consumer cooperatives; charity shops and the fair trade movement; zero carbon housing schemes and community wind farms; restorative justice and community courts. The researchers maintain that all these are examples of social innovation which are characteristically new ideas that work to meet pressing unmet needs and improve peoples' lives. They maintain that social innovations are essentially about old and new methods for mobilising the ubiquitous intelligence that exists within any society. They see the development of social innovation as an urgent task and one of the most urgent that is needed within the society. In a society in which there is a wide, and probably growing, gap between the scale of the problems faced and the scale of the solutions on offered, new methods for advancing social innovation are relevant in every sector but are likely to offer most in fields where problems are intensifying (from diversity and conflict, to climate change and mental illness), in fields where existing models are failing or stagnant (from traditional electoral democracy to criminal justice), and in fields where new possibilities (such as mobile technologies and open source methods) are not being adequately exploited. This study sought to assess the role of social innovation in the relationship between socio-cultural practices and community empowerment with a specific focus on hotel enterprises along the tourism circuit in Kenya.

\section{HYPOTHESIS}

The following hypotheses were tested at 95\% level of significance:

$\mathbf{H}_{01}$ : Socio-cultural practices of hotel enterprises have no significant influence on empowerment of communities at the coastal tourism circuit in Kenya.

Ho2: Social innovations practiced by hotel enterprises have no mediating role on empowerment of communities at the coastal tourism circuit in Kenya

\section{METHODOLOGY}

Design: The study is quantitative in nature to allow examination of the influence of hotel enterprises socio-cultural practices (Independent variable) and community empowerment (Dependent variable). A structured survey research design was adopted in which managers of hospitality and tourism enterprise, beneficiaries of community empowerment programs were provided with anonymous questionnaire to share their experiences.

Participants: Participants included general managers of hotel enterprises, employees from the local community, suppliers of goods and services to the facilities including beach operators and the civic leaders drawn from coastal tourism circuit in Kwale, Mombasa and Kilifi counties.

Data Collection Procedure: Approval was obtained from the University and at the National Commission for Science, Technology and Innovation. The process for getting the approval involved application to the Kenya Methodist University and NACOSTI. Thereafter, consent was sought from the County Commissioner and County Director of Education in the three counties of Mombasa, Kilifi and Kwale. Lastly, informed consent was sought from each study participant through a letter. Subsequently, self-administered questionnaire was distributed to the participants. Key informant interview was conducted with the civic leaders. 
Measures: Information on the influence of hoteliers socio-cultural practices on community empowerment were sought based on respondents' demographic characteristics, social cultural practices, social innovations and community empowerment.

1. Demographics: Information on age, gender and designation of the respondents were assessed.

2. Social cultural practices: Sixteen items measured the extent of the hotel enterprises involvement in socio-cultural practices (SCP). Elements of the variable were subdivided into preservation of local culture (PLC), promotion of local heritage (PLH) and adherence to existing legal framework (ALF) sub-scales. The ratings were made on a 5point scale. Mean scores were computed for the variable.

3. Social Innovations: Five items assessed the social innovations (SI) that the hotel enterprises had adopted. Elements of the variable were sub-divided into welfare (W) and equity (E) sub-scales. The ratings were made on a 5-point scale. Mean scores were computed for the variable.

4. Community Empowerment: Seven items assessed the perceived level of community empowerment (CE) attributed to hotel enterprises. The ratings were made on a 5-point scale. Mean scores were computed for the variable.

\section{DATA ANALYSIS}

The data obtained was both descriptively and inferentially. Mean, standard deviation and Pearson's correlation were used to describe the data. Inferentially, logistic regression was used for objective 1 while hierarchical regression for hypothesis 2 . Specifically, logistic regression was used to test the existing relationship between hotel enterprises socio-cultural practices and community empowerment. Hierarchical regression analysis was used to assess the mediating effect of social innovations adopted by the hotel enterprises on the relationship between socio-cultural practices and community effect. In each case, the hypotheses were tested at 0.05 level of significance.

\section{Demographic Information and Descriptive}

\section{RESULTS AND DISCUSSION}

Demographic information reviewed include location of the enterprise, length of operation and membership/classification status for hotel enterprises while for the beneficiaries designation, age, gender and work experience were considered. Information obtained illustrated that more than three quarters of the enterprises (85.7\%) were members of the association as compared to who were not. At the same time, slightly more of the enterprises $(54.8 \%)$ were classified facilities. With regard to location, more of the enterprises were drawn from Mombasa (45.3\%) and Kwale (33.3\%) as compared to those from Kilifi (21.4\%). Lastly, more than three quarters of the enterprises (76.2\%) had been in operation for either between 10 and 20 years or for more than 20 years. With regard to the respondents, data was obtained from 210 respondents including enterprise management, employees, suppliers and beach operators plying their trade around the enterprises. A significant majority (73.8\%) were male compared to females (26.2\%), a majority were either youths or in middle age (77.6\%) indicating a young and vibrant workforce and except for a paltry $20 \%$ who were in management positions, the rest were beneficiaries. Lastly, information obtained illustrated that more than six out of ten of the respondents had more than ten years of work experience and thus could provide credible information required for the study. At the same time, five civic leaders participated in the interview and thus provided qualitative data for the study. They were drawn from Diani and Tiwi in Kwale, Nyali and Shanzu in Mombasa and Malindi. The civic leaders had work experience ranging from 2 to 12 years and consisted of 4 males and 1 female. Table 1 presents the findings of mean, standard deviation and Pearson's correlation of the study variables. 
Table 1: Means, standard deviations, and correlations of the study variables $(\mathrm{N}=\mathbf{2 1 0})$

\begin{tabular}{|c|c|c|c|c|c|c|c|c|c|c|}
\hline Variables & Mean & SD 1 & 2 & 3 & 4 & 5 & 6 & 7 & 8 & \\
\hline 1. PLC & 4.18 & .690 & . & $.811^{* *}$ & $.765^{* *}$ & $.942^{* *}$ & $.467^{* *}$ & $.512^{* *}$ & $.516^{* *}$ & $.610^{* *}$ \\
\hline 2. PLH & 3.77 & 1.17 & & - & $.901^{* *}$ & $.905^{* *}$ & 712 ** & $.713^{* *}$ & $.735^{* *}$ & $.744^{* *}$ \\
\hline 3. ALF & 3.83 & 1.18 & & & - & $.911^{* *}$ & $.666^{* *}$ & $.706^{* *}$ & $.711^{* *}$ & $.730^{* *}$ \\
\hline 4. SCP & 4.30 & .620 & & & & - & $.513^{* *}$ & $.600^{* *}$ & $.589 * *$ & $.625^{* *}$ \\
\hline 5. Welfare & 3.10 & 1.31 & & & & & - & $.875^{* *}$ & $.957^{* *}$ & $.772^{* *}$ \\
\hline 6. Equity & 3.43 & 1.21 & & & & & & - & $.978^{* *}$ & $.793^{* *}$ \\
\hline 7. SI & 3.30 & 1.21 & & & & & & & - & $.809^{* *}$ \\
\hline 8. $\mathrm{CE}$ & 3.20 & 1.24 & & & & & & & & - \\
\hline
\end{tabular}

**. Correlation is significant at the 0.01 level (2-tailed).

Findings show that SCP reported highest level of adoption $(M=4.30, S D=.620)$, SI was higher $(\mathrm{M}=3.30 \mathrm{SD}=1.21)$ while $\mathrm{CE}$ was high $(\mathrm{M}=3.20, \mathrm{SD}=1.24)$. SCP was found to be strongly and significantly correlated to CE $(\mathrm{r}=.625, \mathrm{p}=<.01)$ and SI $(\mathrm{r}=.589, \mathrm{p}<.01)$. As was expected, it was positively and significantly correlated to PLC $(\mathrm{r}=.942, \mathrm{p}<.01)$, PLH $(\mathrm{r}=.905, \mathrm{p}<.01)$ and ALF $(\mathrm{R}=.911, \mathrm{p}<.01)$. SI was also positively and significantly correlated $\mathrm{CE}(\mathrm{r}=.809, \mathrm{p}<.01)$.

\section{Hypothesis 1: Socio-cultural practices of hotel enterprises have no significant influence on empowerment of communities at the coastal tourism circuit in Kenya.}

First and foremost, the study intended to assess the influence of SC practices adopted by hotel enterprises within the coastal tourism circuit on empowerment of communities. To achieve this, respondents' score for adoption of SC practices by hotel enterprises were regressed against categorized CE in a binary logistic regression model. Findings were as presented in Table 2 .

Table 2: Influence of SC Practices on Community Empowerment

\begin{tabular}{lcccccc}
\hline Variables & B & SE & Wald's $\boldsymbol{\chi}^{\mathbf{2}}$ & df & Sig. & Exp(B) \\
\hline PLC & .616 & .702 & .769 & 1 & .380 & 1.851 \\
PLH & 1.633 & .680 & 5.770 & 1 & .016 & 5.120 \\
ALF & -.190 & .651 & .085 & 1 & .771 & .827 \\
Constant & -7.285 & 2.078 & 12.293 & 1 & .000 & .001 \\
\hline
\end{tabular}

a. Variable(s) entered on step 1: PLC, PLH, ALF.

The independent variables in the model were SCP sub-scales: PLC, PLH and ALF. The model was significant, $\chi^{2}(3)=26.05, p<0.001$ and the Hosmer and Lemeshow Test confirmed model fit, $\chi^{2}(7)=11.84, p=0.106$. Findings led to the rejection of the hypothesis. Cox \& Snell R Square predicted a variance of $26.2 \%$ while Nagelkerke R Square predicted $39.1 \%$ in variation in community empowerment explained by the model. The model with independent variables explained $83.3 \%$ of community empowerment due to SC practices, an improvement from the $75.9 \%$ initially predicted. PLH significantly predicted CE, $\chi^{2}$ Wald $(1)=5.77, p=0.016, \operatorname{Exp}(B)=$ 5.12) while it dropped by $13.0 \%$ due to ALF. Though insignificant, PLC increased the odds of CE by $85.1 \%$. Generally, previous studies in acknowledging the possible impacts of socioentrepreneurial practices on host communities along the socio-cultural front have attempted to highlight best practices and at times shortcomings especially among the less developed and emerging economies (Stankova, Dalmeijer \& Elzerman, 2005). According to the researchers, most projects are development projects aimed at preserving -or at least, minimising negative impacts on the indigenous culture. This is supported by Mason (2012) who emphasises that for effective conservation (as for development), the task is to devise culturally appropriate strategies. Enterprises implementing these projects would not succeed if they try to impose their goals without considering the practices, customs, rules, laws, beliefs, and values of the 
people to be affected. In tourism industry, socio-cultural sustainability is concerned with the social interaction, relations, behavioral patterns and values between people (Roberts \& Tribe, 2008; Mason, 2012).

\section{Hypothesis 2: Social innovations practiced by hotel enterprises have no mediating role on empowerment of communities at the coastal tourism circuit in Kenya}

The hypothesized mediating role of SI in the relationship between SC practices and CE was tested based on a regression analysis in a 4 step process and findings were as presented in Table 3.

Table 3: Influence of SI in the Relationship between SC and CE

\begin{tabular}{lcccccccc}
\hline Variable & $\mathbf{R}^{\mathbf{2}}$ & $\mathbf{d f 1}$ & $\mathbf{d f 2}$ & $\mathbf{F}$ & Sig. & $\boldsymbol{\beta}$ & t & Sig. \\
\hline SC vs CE & .391 & 1 & 208 & 67.980 & .000 & .962 & 8.245 & .000 \\
SI vs SC & .347 & 1 & 208 & 56.226 & .000 & .389 & 7.498 & .000 \\
SI vs CE & .655 & 1 & 208 & 395.318 & .000 & .830 & 19.883 & .000 \\
SC vs CE & .391 & 1 & 208 & 67.980 & .000 & .962 & 8.245 & .000 \\
with SI & .651 & 2 & 207 & 98.081 & .000 & .390 & 3.553 & .001 \\
\hline
\end{tabular}

First, SC was regressed against CE. The model obtained which was significant, $F(1,208)=67.98$, $\mathrm{p}<0.001$ indicated that SC accounted for $39.1 \%$ of variation in CE. Findings illustrated that SC positively and significantly predicted CE $(\mathrm{t}=8.25, \mathrm{p}<0.001)$. Secondly, SI was regressed against SC practices. The second model was also significant, $F(1,208)=56.23, \mathrm{p}<0.001$ and illustrated that SI accounted for $34.7 \%$ of total variance in SC practices. In the model, SI positively and significantly predicted SC practices, $(\mathrm{t}=7.50, \mathrm{p}<0.001)$. Similar observation was made with regard to the third model assessing the relationship between SI and CE, the model $F(1$, $208)=395.32$, $p<0.001$ accounting for $65.5 \%$ of variation in CE. In the model, SI positively and significantly predicted CE, $(\mathrm{t}=19.88, \mathrm{p}<0.001)$. In the fourth model, SC practices and SI were regressed against CE hierarchically, first by introducing SC practices followed by SI. Introduction of SI in the SC and CE model increased the variation in CE by $26.1 \%, F(1$, $208)=78.49, p<0.001$ the model being significant. The contribution of SC practice dropped from the initial $(\beta=0.962, p<0.001)$ to $(\beta=0.390, p=0.001)$. The findings thus illustrates that SI partially mediates the relationship between SC practices and CE. This led to the rejection of the second hypothesis. The findings are in line with the observations of Petrou and Daskalopoulou, (2013) who maintains that social innovation has the potential to provide solutions in various sectors, tourism included as an important developmental factor. Social innovation is a source of social solutions in tourism concerned with transferring innovation knowledge and providing products, services and solutions to the needs of the tourists and community stakeholders. Mulgan et al. (2007) observed that outcomes of social innovation are everywhere and are essentially about old and new methods for mobilising the ubiquitous intelligence that exists within any society. The researchers see the development of social innovation as an urgent task and one of the most urgent that is needed within the society. In a society in which there is a wide, and probably growing, gap between the scale of the problems faced and the scale of the solutions on offered, new methods for advancing social innovation are relevant in every sector but are likely to offer most in fields where problems are intensifying (from diversity and conflict, to climate change and mental illness), in fields where existing models are failing or stagnant (from traditional electoral democracy to criminal justice), and in fields where new possibilities (such as mobile technologies and open source methods) are not being adequately exploited. 


\section{CONCLUSIONS}

The study assessed the influence of hotel enterprises' socio-cultural practices on community empowerment along the coastal tourism circuit in Kenya. It illustrated that the enterprises' socio-cultural practices significantly influence community empowerment. In particular, the study showed that preservation of local culture and promotion of local heritage as sub-scales of socio-cultural practices positively influence community empowerment, the influence of promotion of local heritage being significant. Further, findings illustrated that social innovations adopted by hotel enterprises partially mediates the influence of socio-cultural practices on community empowerment. The study therefore recommends that adoption of socio-cultural practices be given more attention by the hotel enterprises since their adoption as socio-entrepreneurial practices has tangible benefits on empowerment of local communities within which the enterprises operate. In the processes, due regard should be given to an enhanced adoption of elements of adherence to legal framework to turnaround their negative influence as well as enhanced adoption of elements of preservation of local culture.

\section{References}

Birch, J. C., Thapa, I., Balmford, A., Bradbury, R. B., Brown, C., Butchart, S. H., .. \& Peh, K. S. H. (2014). What benefits do community forests provide, and to whom? A rapid assessment of ecosystem services from a Himalayan forest, Nepal. Ecosystem Services, 8, 118-127.

Bisson, P., Stephenson, E., \& Viguerie, S. P. (2010). The productivity imperative. McKinsey Quarterly, 1-7.

Bliss, S. (2006). Child labour in tourism industry in developing countries. Social Educator.

Britton, S. G. (1982). The political economy of tourism in the Third World. Annals of tourism research, 9(3), 331358.

Carlisle, S., Kunc, M., Jones, E., \& Tiffin, S. (2013). Supporting innovation for tourism development through multistakeholder approaches: Experiences from Africa. Tourism Management, 35, 59-69.

Chissim, F. (1996). An exploratory and Descriptive Research on Child Prostitution and Tourism in Kenya. EPAT Report.

ECPAT International (2007) 'Preventing Child Sex Tourism', Retrieved 17th June, 2007 from http://www.ecpat.net/eng/Ecpat inter/projects/sex tourism/sex tourism.asp, ECPAT International

Enloe, C. (2002). The prostitute, the colonel and the Nationalist. Enloe, Cynthia: Maneuvers: The international politics of militarising women's lives: London and Los Angeles: University of California Press (2nd Edition), 19-41.

Howaldt, J., \& Kopp, R. (2012). Shaping social innovation by social research. In Challenge of Social Innovation. Springer, Berlin, Heidelberg.

ILO (1999). Global report. www.ilo.org/global/topics/child-labour/lang--de/index.htm

IPEC (2009). Eradication of child labour in tourism. Global report. www.ilo.org/ipec/lang--en/index.htm

Jones, C. S. (2006). The extent and effect of sex tourism and sexual exploitation of children on the Kenyan coast. UNICEF.

Laeis, G. C., Laeis, G. C., Lemke, S., \& Lemke, S. (2016). Social entrepreneurship in tourism: Applying sustainable livelihoods approaches. International Journal of Contemporary Hospitality Management, 28(6), 1076-1093.

Mason, C. (2012). Up for grabs: A critical discourse analysis of social entrepreneurship discourse in the United Kingdom. Social Enterprise Journal, 8(2), 123-140.

Mosedale, J., \& Voll, F. (2017). Social Innovations in Tourism: Social Practices Contributing to Social Development. In Social Entrepreneurship and Tourism (pp. 101-115). Springer, Cham.

Moufakkir, 0. (2012). Of Ethics, Leisure and Tourism: The 'Serious Fun of Doing Tourism.'. Controversies in tourism, 7-22.

Mulgan, G., Tucker, S., Ali, R., \& Sanders, B. (2007). Social innovation: what it is, why it matters and how it can be accelerated. Skoll Centre for Social Entrepreneurship Working paper

Nadda, V. K., Dadwal, S. S., Mulindwa, D., \& Vieira, R. (2015).Role of Social Media in Tourism.Handbook of Research on Global Hospitality and Tourism Management, 142. 
Omondi, R. K. (2003). Gender and the political economy of sex tourism in Kenya's coastal resorts.

Pace, L. A. (2016). How do tourism firms innovate for sustainable energy consumption? A capabilities perspective on the adoption of energy efficiency in tourism accommodation establishments. Journal of Cleaner Production, 111, 409-420.

Petrou, A., \& Daskalopoulou, I. (2013). Social capital and innovation in the services sector. European Journal of Innovation Management, 16(1), 50-69.

Plüss, C., \& Tourismus, A. (1999). Quick Money-Easy Money. A report on child labour in tourism.

Praničević, D. G., \& Peterlin, J. (2015). Communication with the stakeholders in sustainable tourism. In Proceedings of the 3rd International Scientific Conference Tourism in Southern and Eastern Europe 2015 (ToSEE) (pp. 63-74).

Richards, G., \& Hall, D. (Eds.). (2003). Tourism and sustainable community development (Vol. 7). Psychology Press.

Roberts, S., \& Tribe, J. (2008).Sustainability indicators for small tourism enterprises-An exploratory perspective. Journal of sustainable tourism, 16(5), 575-594.

Roblek, V., Stok, Z. M., \& Mesko, M. (2016, January). Complexity of a sharing economy for tourism and hospitality. In Faculty of Tourism and Hospitality Management in Opatija. Biennial International Congress. Tourism \& Hospitality Industry (p. 374). University of Rijeka, Faculty of Tourism \& Hospitality Management.

Ryan, C., \& Hall, C. M. (2001). Sex tourism. Special Interest Tourism, Queensland: John Wiley and Sons Australia Ltd.

Scott, L., Williams, J. D., Baker, S. M., Brace-Govan, J., Downey, H., Hakstian, A. M., ... \& Webb, D. (2011). Beyond poverty: Social justice in a global marketplace. Journal of Public Policy \& Marketing, 30(1), 39-46.

Sigala, M., \& Kyriakidou, O. (2015). Creativity and innovation in the service sector. The Service Industries Journal, 35(6), 297-302.

Swarbrooke, J. (1999). Sustainable tourism management.Cabi.

van Oort, F. G., \& Lambooy, J. G. (2014). Cities, knowledge, and innovation. In Handbook of Regional Science (pp. 475-488). Springer Berlin Heidelberg. 